\title{
Can Employees Get Proper Performance Evaluation if They Speak Out? — the Moderating Effects of Leader'S Psychological Characteristics
}

\author{
Jin Cheng ${ }^{1, a}$, Yanwen $\mathrm{Jin}^{2, \mathrm{~b}}$, Yan Cheng ${ }^{3}$ and Yingying Chen ${ }^{4}$ \\ ${ }^{1,2,3,4}$ School of Management, Xiamen University, Xiamen, 361005, China \\ achengjin1025@xmu.edu.cn, bjyw1993@foxmail.com
}

\begin{abstract}
Keywords: Employee voice; Performance evaluation; Leader's power distance; Leader's performance orientation; Leader's reflection ability

Abstract. Voice could be utilized as an effective method to improve organizational effectiveness. However, employees will hesitate to speak out because of possible adverse outcomes. This study explores the relationship between the employee voice and performance evaluation rated by their superiors. The paper posits that the leader's power distance, performance orientation, and reflection ability moderate the relationship between voice and performance evaluation. When the leader has lower power distance, higher performance orientation, and higher reflection ability, they will appraise the employee's performance higher when employee voices the concerns of the organization.
\end{abstract}

\section{Introduction}

Nowadays the business world was considerably more volatile, uncertain and complex, solely relying on managers has been unable to solve all the problems the organization is faced with. It is significant for the organization to fully arouse the staffs' enthusiasm to put forward their suggestions innovation and change (Morrison,2011) [1]. However, when it comes to the key issues of organizational development, a multitude of employees may choose to keep silent, fearing that voicing may bring the risks to their image, interpersonal relationship, and career development, even if they know more about these issues (Chris Rees et al.,2013) [2]. Does the voice behavior always lead to the loss of personal interest? On the one hand, some studies demonstrated that managerial reactions had reported positive outcomes associated with prosocial forms of voice (Whiting et al., 2008) [3]. On the other hand, some researchers have reported the adverse effects (Ethan R. et al.,2013) [4], or the mixed results about the voice behavior (Jen-Wei Cheng et al., 2013) [5]. The inconsistent view of the relationship between employee voice behavior and performance evaluation provides the opportunity for this study. Whether the employee will get the proper appraisal depends on how the leaders attribute the voice. If they think the voicer is a helper of the organization, they will give a higher performance appraisal rating to the employees. On the contrary, if they believe the voicer a trouble-maker of the organization, the employees will get the lower performance appraisal. The leader's psychological characteristics will affect the attribution of the leaders.

Therefore, this paper tries to explore what kinds of psychological characteristics of the leader will affect the employees' performance appraisal rating by the leaders.

\section{Hypotheses Development}

Recent research has shown that leaders play a vital role in the voice process because they are perceived to have the power to address the issues voicer concerns (Ashford et al.,2009; Jen-Wei Cheng et al., 2013) [5][6]. Given the significant roles of leaders in developing a climate of silence or voice (Morrison \& Milliken, 2000) [7], it is important to examine how leaders react to employees who speak up. Since the psychological characteristics of the leaders will influence their cognition towards the employee's voice behavior, our research incorporates the leader's power distance, performance 
orientation and reflection ability as the moderators of the relationship between employee voice behavior and performance evaluation rating by their leaders.

\section{The Moderating Role of Leader's Power Distance}

Power distance is defined as the recognition and acceptability of unfair distribution of power in society to measure the emotional distance between the power and the weak (Mulder,1977) [8]. The leader's power distance influences the leader's attitudes and behaviors. Previous studies have demonstrated that power distance of leaders has a significant negative impact on their empowering behaviors, and leaders with high power distance focus on maintaining its authority within the organization, rather than powersharing (Isabel \& Linn Van Dyne) [9].

The leader of high power distance identified the rationality of the power inequality between the superior and the inferior (Farh et.al., 2007) [10]. They would lay more emphasis on the power of controlling subordinates, enabling employees to follow their ideas. Notably, leaders of high power distance usually avoid negative opinions from subordinates as far as possible, in consideration of the threats of making themselves appear incompetent and weakening their authority within the organization (Harris, 2006) [11]. Therefore, even if the employees' advice is beneficial to the organization, the leaders will focus on the egoism of the employees rather than their altruistic motives. Thus when the leaders rate the performance of employees who speak up, the employees will get the lower scores or ratings. On the contrary, for the leaders with low power distance, it is far more likely for them to adapt to the equal relationship between the upper and lower levels, treating the voicer actively. Based on these arguments, we put forward the following hypothesis:

Hypothesis 1: The leader's power distance negatively moderates the relationship between employee voice behavior and performance evaluation rating by the leaders.

\section{The Moderating Role of Leader's Performance Orientation}

The leader's performance orientation is part of the leader's work value. It shows his lasting belief in the work and performance which will affect the leader's preference behavior pattern. If the leader is performance-oriented, which means the leader is pursuing of achievement and performance, usually he will think highly of the employee voice behavior. He will take the employee voice as a good opportunity to improve his work and achieve the high performance. Even though the voicer offends him, he will pay attention to the positive aspects of voicing, ignoring the unpleasant feelings in the voice process. Creative thinking and creative process caused by the employee voice behavior can be useful to the leader, leading to the team and organizational performance improvement. (Philip M. P, 2012) [12]. A performance-oriented leader will affirm the commitments and abilities of the voicer from his voice behavior. Therefore, when the leader with performance-orientation evaluates the performance of employees who speak up, he will improve the level of performance of voicer.

Therefore, we put forward the following hypothesis:

Hypothesis 2: The leader's performance-orientation positively moderated the relationship between employee voice behavior and performance evaluation rating by the leaders

\section{The Moderating Role of Leader's Reflection Ability}

Reflection is a kind of thinking activity, including problem identification, analysis and solving. O'Neill (1997) pointed out that the reflection of the leaders can clearly help them understand oneself and change oneself with the exploratory attitude [13]. Miehlsd and Moffattk (2000) pointed out that the reflective ability contributed to enhancing the individual's ability of insight in practice [14]. The reflective ability can help one to identify, analyze and solve the problem. The leader's reflection ability 
refers to a trait that the leader can explore his /her psychological world with the exploratory attitude, and make suitable self-adjustment. The leaders with high reflection ability have the desire and interest to improve themselves, so they welcome the voice and critics. When the employees voice their concerns or suggestions about the organization, the leaders will appraise the employees with a more positive attitude. To sum up, this paper puts forward the following hypothesis:

Hypothesis 3: The leader's reflection ability positively moderated the relationship between employee voice behavior and performance evaluation.

\section{Theoretical Model}

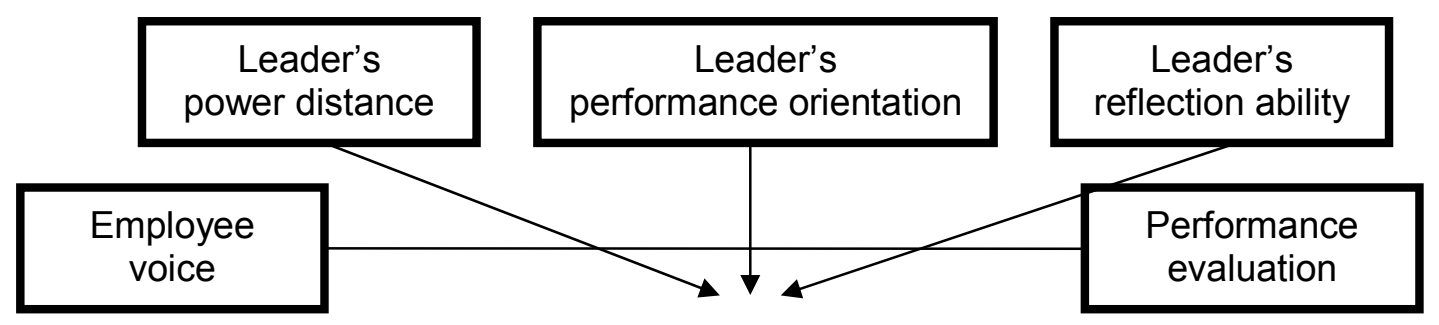

Figure 1. Finite Theoretical Model

\section{Summary}

The possible adverse outcomes brought by the voice behavior affect the employee voice behavior. This paper wants to explore what kinds of psychological characteristics of leaders affect the relationship between employee voice behavior and performance appraisal rated by the leaders. This article put forward three hypotheses. First, the leader's power distance negatively moderated the relationship between employee voice and the performance evaluation rated by the leaders. Second, the leader's performance orientation positively moderated the relationship between employee voice and the leader's performance evaluation rated by the leaders. Third, the leader's reflection ability positively moderated the relationship between employee voice and the performance evaluation rated by the leaders. The paper provides a new perspective to study the employee voice and propose that whether the employee voice behavior leads to the adverse performance appraisal depends on the leader's psychological characteristics. The empirical research about these hypotheses could be carried on in the future.

\section{References}

[1] Morrison, E.W., Wheeler Smith, S.L.\& Kamdar, Speaking up in groups: a cross-level study of group voice climate and voice. [J] Journal of Applied Psychology, 2011.

[2] Chris Rees, Kerstin, A \& Mark, G, Employee voice and engagement: connections and consequences. [J] The International Journal of Human Resource Management, 2013.Vol. 24, No. 14, 2780-2798.

[3] Whiting, P \& Pierce, J. R. 2008. Effects of task performance, helping, voice, and organizational loyalty on performance appraisal ratings. [J] Journal of Applied Psychology, 93: 125-139.

[4] Ethan R, James R. \& Alexander C., Speaking Up vs. Being Heard: The Disagreement Around and Outcomes of Employee Voice. [J] Organization Science. Vol. 24, No. 1, January-February 2013, pp. 22-38.

[5] JW Cheng, KM Lu, YY Chang, Steward Johnstone, Voice behavior and work engagement: the moderating role of supervisor-attributed motives. [J] Australian Human Resources Institute. (2013) $51,81-102$. 
[6] Ashcraft, K. L., Kuhn, T. R., \& Cooren, F. 2009. Constitutional amendments: Materializing organizational communication. [J] Academy of Management annals, vol. 3: 1-64. Essex, U.K.: Routledge.

[7] Morrison, E. W., \& Milliken, F. J. 2000. Organizational silence: A barrier to change and development in a pluralistic world. [J] Academy of Management Review, 25: 706-31.

[8] Mulder \& Mauk .1977. The Daily Power Game. International series on the quality of working life. [J] Leiden, the Netherlands: Martinus Nihoff Social Sciences Division. 1007/978.

[9] Isabel C. \& Linn VD. Employee Voice Behavior Interactive Effects of LMX and Power Distance in the United States and Colombia. [J] Management Communication Quarterly. June 3, 2009.

[10]Farh, J.L., Hackett, R. D., \& Liang, J. (2007). Individual-level cultural values as moderators of perceived organizational support-employee outcome relationship in China: Comparing the effects of power distance and traditionality. [J] Academy of Management Journal, 50(3), 715.

[11] Georgesen \& Harris, 2006. Holding onto power: effects of powerholders positional instability and expectancies on interactions with subordinates. [J] Eueopean Jounal of Social Psycology. Volume 36, Issue 4,451-468.

[12]Philip M. P. Effects of Message, Source, and Context on Evaluations of Employee Voice Behavior. [J] Journal of Applied Psychology .2012, Vol. 97, No. 1, 159-182.

[13] O'Neill, R. M., Hayes, E., \& Wierha, E. E. 1997. Reading the wind: How middle managers assess the context for selling issues to top managers. [J] Strategic Management Journal, 18: 407-423.

[14] Miehlsd \& Moffattk, Constructing Social Work Identity Based on the Reflexive Self. [J] British Journal of Social Work, 2000(3):339-348. 